\title{
GENTRIFICAÇÃO, A FRONTEIRA E A REESTRUTURAÇÃO DO ESPAÇO URBANO
}

\author{
Neil Smith ${ }^{1}$ \\ Tradução: Daniel de Mello Sanfelici*
}

\section{RESUMO:}

Neste ensaio, o autor procura explicar o processo da gentrificação, situando o fenômeno no quadro mais amplo do desenvolvimento desigual da economia capitalista. Coloca em evidência, nesse sentido, a articulação das diferentes escalas, as mudanças sociais recentes e os ciclos econômicos, fatores que atuam na determinação da natureza, da forma assumida e dos limites do processo. Por fim, o autor identifica tendências e obstáculos associados ao desdobramento futuro da gentrificação.

\section{PALAVRAS-CHAVE:}

gentrificação; fronteira; desenvolvimento desigual.

\section{ABSTRACT:}

In this essay the author tries to explain the process of gentrification, situating the phenomenon in the broader scope of the uneven development in the space economy of capitalism. In this sense, he puts in evidence the articulation of different scales, the recent social changes, and the economic cycles; factors which act upon the determination of nature, the assumed form, and the limits of the process. Finally, the author identifies tendencies and obstacles associated with the unfolding future of gentrification.

\section{KEY WORDS:}

gentrification; frontier; uneven development.

Em seu ensaio seminal "The significance of the frontier in American history", escrito em 1893, Frederick Jackson Turner (1958) escreveu:

o desenvolvimento americano exibiu não apenas um avanço sobre uma linha única, mas um retorno a condições primitivas em uma linha de fronteira que avança continuamente, e um novo desenvolvimento para aquela área. $O$ desenvolvimento social americano tem reiniciado continuamente na fronteira... Neste avanço, a fronteira é o limite externo deste movimento - o ponto de encontro entre a barbárie e a civilização... O mundo selvagem tem sido perpassado por linhas de civilização que são cada vez mais numerosas.
Para Turner, a expansão da fronteira e o recuo da natureza virgem e da barbárie foram uma tentativa de criar um espaço habitável a partir de uma natureza hostil e não cooperativa. Isto compreendeu não apenas um processo de expansão espacial e a progressiva dominação do mundo físico. O desenvolvimento da fronteira sem dúvida realizou isto, mas para Turner este desenvolvimento também foi a experiência central que definiu a singularidade da identidade nacional americana. Em cada avanço do limite externo realizado por pioneiros robustos, não apenas novas terras eram acrescentadas, mas novo sangue era inserido nas veias do ideal democrático americano. Cada nova onda em direção ao oeste, na conquista da natureza, devolve para leste ondas de retorno no sentido 
da democratização na natureza humana.

Durante o século $X X$ a imagem do lugar selvagem e da fronteira foi aplicada menos às planícies, montanhas e florestas do Oeste, e mais às cidades do país todo, mas especialmente àquelas do Leste. Como parte da experiência da suburbanização, a cidade americana veio a ser vista, pela classe média branca, como um lugar selvagem; a cidade era, e ainda é para muitos, o habitat da morbidade social e do crime, do perigo e da desordem (Warner, 1972). De fato, estes eram medos manifestados, durante os anos 50 e 60, por teóricos urbanos que punham em evidência a "influência maléfica" e a "decadência" urbana, "o mal-estar social" na área central, a "patologia" da vida urbana; em resumo, a "cidade infernal" (Banfield, 1968). A cidade se torna um lugar selvagem, ou pior, uma selva (Long, 1971; Sternlieb, 1971; ver também Castells, 1976a). Mais ainda do que nos noticiários e na teoria social, este tema é recorrente em produções hollywoodianas do gênero "selva urbana", desde Amor, sublime amor e King Kong até Warriors - os selvagens da noite.

O anti-urbanismo tem sido uma teoria dominante na cultura americana. Em um padrão análogo à experiência original da conquista do Oeste selvagem, os últimos 20 anos assistiram a um deslocamento do medo em direção ao romantismo e uma progressão da imagem urbana de lugar selvagem para a idéia de fronteira. Cotton Mather e os puritanos da Nova Inglaterra no século XIX temiam a floresta como o mal impenetrável, uma perigosa selva, mas com a progressiva dominação da floresta e sua transformação através do trabalho humano, a imagem mais suave de fronteira - de Turner torna-se uma sucessora óbvia desta imagem de floresta do mal de Mather. Existe um otimismo e uma perspectiva de expansão associada à "fronteira"; a barbárie dá lugar à fronteira quando a conquista está em curso. Portanto, na cidade americana do século $X X$, a imagem da selva urbana foi substituída por aquela da fronteira urbana. Esta transformação pode ser identificada nas origens da renovação urbana (ver especialmente Abrams, 1965), mas se intensificou nas últimas duas décadas, quando a restauração de habitações unifamiliares virou moda na esteira da renovação urbana. Na linguagem da gentrificação, o apelo à imagem de fronteira é exato: pioneiros urbanos, proprietários urbanos e caubóis urbanos são os novos heróis folclóricos da fronteira urbana.

Assim como Turner reconheceu a existência dos nativos, mas os incluiu do lado selvagem, a imagem contemporânea da fronteira urbana implicitamente trata os atuais moradores da área central como um elemento natural do meio físico a que pertencem. Portanto, o termo "pioneiro urbano" é tão arrogante quanto a noção original de "pioneiro", visto que ele transmite a idéia de uma cidade que ainda não é socialmente habitada; assim como os americanos nativos, a classe trabalhadora urbana de hoje é vista como menos do que social, como uma simples parte do meio físico. Turner foi explícito a esse respeito quando definiu a fronteira como "o ponto de encontro entre a barbárie e a civilização" e, embora o vocabulário contemporâneo da fronteira aplicado à gentrificação seja raramente tão explícito, ele trata a população das áreas centrais da mesma maneira (Stratton, 1977).

Os paralelos vão mais longe. Para Turner, o avanço geográfico da linha de fronteira em direção ao oeste é associado à construção do espírito nacional. Uma esperança espiritual expressa-se também no discurso entusiástico que apresenta a gentrificação como a pontade-lança de um renascimento urbano americano; no cenário mais extremo, esperase que os novos pioneiros façam pelo espírito nacional o mesmo que os antigos fizeram: conduzir-nos a um novo mundo no qual os problemas do mundo velho são deixados para trás. Nas palavras de uma publicação do governo federal, o apelo da gentrificação à história envolve a "necessidade psicológica de experimentar novamente os êxitos do passado em virtude das decepções dos anos recentes a guerra do Vietnam, o caso Watergate, a crise de energia, a inflação, as altas taxas de juros, 
etc" (Advisory Council on Historic Preservation, 1980:9). Ninguém, até o momento, propôs que James Rouse (o investidor americano responsável por muitos visíveis shoppings, centros comerciais, mercados e galerias para turistas) fosse visto como o John Wayne ${ }^{2}$ da gentrificação, mas a proposta estaria em harmonia com muito da atual imagem retórica da gentrificação. Por fim, e esta é a conclusão importante, a imagem de fronteira serve para racionalizar e legitimar um processo de conquista, tanto no caso do Oeste americano nos séculos XVIII e XIX quanto no caso das áreas centrais das cidades do século $X X$. A imagem se apóia em muitos mitos, mas também tem uma base parcial na realidade. Parte da mitologia já foi sugerida, mas antes de prosseguir para examinar a base realista da imagem de fronteira, gostaria de discutir um aspecto da mitologia da fronteira ainda não considerado: o nacionalismo.

O processo de gentrificação com o qual estamos preocupados, aqui, é essencialmente internacional. Ele está ocorrendo na América do Norte e em grande parte da Europa ocidental, assim como na Austrália e na Nova Zelândia, ou seja, nas cidades da maior parte do mundo capitalista ocidental avançado. Apesar disto, em nenhum lugar o processo é tão pouco compreendido quanto nos Estados Unidos, onde o nacionalismo americano presente na ideologia de fronteira incitou um entendimento provinciano da gentrificação. A experiência original de fronteira anterior ao século $X X$ não foi restrita aos Estados Unidos, mas sim exportada para o mundo todo; da mesma forma, embora não esteja em nenhum lugar tão enraizada como está nos Estados Unidos, a ideologia de fronteira também surge em outros locais associada à gentrificação. A influência internacional da experiência americana anterior de fronteira é repetida no caso do panorama urbano do século $X X$; a imagem de gentrificação é, ao mesmo tempo, cosmopolita e paroquial, geral e local. É geral em imagem, mas geralmente diferente nos detalhes. Por estas razões, a crítica da imagem de fronteira não nos obriga a repetir o nacionalismo de Turner, e não deve ser vista como uma base nacionalista para a discussão da gentrificação. A experiência australiana da fronteira, por exemplo, certamente foi diferente da americana, mas também foi responsável (juntamente com a importação da cultura americana) por produzir uma forte ideologia da fronteira. E a própria fronteira americana era tão intensamente real para imigrantes potenciais da Escandinávia ou Irlanda, quanto o era para imigrantes franceses ou britânicos que viviam em Baltimore ou Boston.

Entretanto, como em toda ideologia, há um embasamento real, ainda que parcial e distorcido, para o tratamento da gentrificação como uma nova fronteira urbana. Nesta idéia de fronteira, vê-se uma combinação evocativa das dimensões econômica e espacial do desenvolvimento. A potência da imagem de fronteira depende da sutileza presente nesta combinação do econômico com o espacial. No século XIX, a expansão da fronteira geográfica nos EUA e em outros lugares foi também uma expansão econômica do capital. Contudo, o individualismo social fixado e incorporado à idéia de fronteira é, em um aspecto importante, um mito; a linha de fronteira de Turner foi expandida em direção oeste menos por pioneiros e proprietários individuais do que por bancos, estradas de ferro, o Estado e outros especuladores, e esses, por sua vez, venderam suas terras (com lucro) para empresas e famílias (ver, por exemplo, Swierenga, 1968). Nesse período, a expansão econômica foi realizada em parte por meio da expansão geográfica absoluta, ou seja, a expansão da economia significou a expansão da arena geográfica na qual a economia operava.

Hoje, o vínculo entre o desenvolvimento econômico e geográfico persiste, conferindo à imagem de fronteira sua atualidade, mas a forma deste vínculo é bem diferente. No que diz respeito à base espacial, a expansão econômica ocorre hoje não por meio da expansão geográfica absoluta, mas pela diferenciação interna do espaço geográfico (N. Smith, 1982). A produção atual do espaço ou do 
desenvolvimento geográfico é, portanto, um processo acentuadamente desigual. A gentrificação, a renovação urbana e o mais amplo e complexo processo de reestruturação urbana são todos parte da diferenciação do espaço geográfico na escala urbana; e, embora estes processos tenham sua origem em um período anterior à atual crise econômica mundial, sua função hoje é reservar uma pequena parte do substrato geográfico para um futuro período de expansão (Smith, 1984). E assim como no caso da fronteira original, a mitologia afirma ser a gentrificação um processo liderado por pioneiros e proprietários individuais cujo suor, ousadia e visão estão preparando o caminho para aqueles, entre nós, que são mais temerosos. Mas mesmo que ignoremos a renovação urbana e o redesenvolvimento comercial, administrativo e recreacional que vem ocorrendo, e concentremos-nos apenas na reabilitação residencial, é patente o fato de que, onde quer que os "pioneiros urbanos" se aventurem, os bancos, as incorporadoras, o Estado e outros atores econômicos coletivos geralmente chegam antes. Neste sentido, parece ser mais apropriado ver a James Rouse Company não como o John Wayne, mas como a Wells Fargo $^{3}$ da gentrificação.

Na mídia, a gentrificação tem sido apresentada como o maior símbolo do amplo processo de renovação urbana que vem ocorrendo. Sua importância simbólica ultrapassa em muito sua importância real; é uma pequena parte, embora muito visível, de um processo muito mais amplo. O verdadeiro processo de gentrificação presta-se a tal abuso cultural da mesma forma que ocorreu com a fronteira original. Quaisquer que sejam as reais forças econômicas, sociais e políticas que pavimentam o caminho para a gentrificação, e quaisquer que sejam os bancos e imobiliárias, governos e empreiteiros que estão por trás do processo, o fato é que a gentrificação aparece, à primeira vista, e especialmente nos EUA, como um maravilhoso testemunho dos valores do individualismo, da família, da oportunidade econômica e da dignidade do trabalho (o ganho pelo suor). Aparentemente, ao menos, a gentrificação pode ser tocada de forma a executar alguns dos acordes mais ressonantes de nosso piano ideológico.

Já em 1961, Jean Gottmann não apenas percebeu a existência de configurações urbanas em transformação, mas também falou em uma linguagem receptiva à ideologia emergente, quando afirmou que a "fronteira da economia americana é, nos dias de hoje, urbana e suburbana, em vez de uma fronteira periférica às áreas civilizadas" (Gottmann, 1961: 78). Com duas importantes condições, que se tornaram mais visíveis nas últimas duas décadas, este insight é correto. Em primeiro lugar, a fronteira urbana é, antes de mais nada, uma fronteira no sentido econômico. As transformações políticas, sociais e culturais nas áreas centrais são amiúde intensas e são certamente importantes no que diz respeito à experiência imediata da vida cotidiana, mas elas estão associadas ao desenvolvimento de uma fronteira econômica. Em segundo lugar, a fronteira urbana é, hoje, apenas uma dentre várias fronteiras existentes, visto que a diferenciação interna do espaço geográfico ocorre em diferentes escalas. No contexto da atual crise econômica global, é evidente que tanto o capital internacional quanto aquele de origem americana se defrontam com uma "fronteira" global que abrange a assim chamada fronteira urbana. Este vínculo entre diferentes escalas e a importância do desenvolvimento urbano para a recuperação nacional e internacional ficaram claramente evidentes no linguajar entusiástico usado por apoiadores das Zonas Empresariais [Enterprise zone] urbanas, uma idéia surgida nas administrações Reagan e Thatcher. Para citar apenas um apologista, Stuart Butler (um economista britânico que trabalha para um grupo americano de direita, a Heritage Foundation $)^{4}$ :

Pode-se sustentar que pelo menos parte do problema com o qual se defrontam muitas áreas urbanas hoje reside no fracasso em aplicar o mecanismo explicado por Turner (o contínuo desenvolvimento e renovação locais de idéias) 
... para a "fronteira" das áreas urbanas centrais. As cidades estão enfrentando mudanças fundamentais, e, no entanto, as medidas utilizadas para lidar com estas mudanças são ordenadas, na sua maioria, por governos distantes. Nós falhamos em avaliar que podem existir oportunidades nas próprias cidades, e nós escrupulosamente evitamos conceder, às forças locais, a chance de aproveitá-las. Os proponentes da Zona Empresarial visam proporcionar um ambiente onde o processo de fronteira possa ser colocado em prática na própria cidade. (Butler, 1981: 3)

A observação circunspecta de Gottmann e outros abriu espaço, vinte anos mais tarde, para a adoção escancarada da "fronteira urbana" como o núcleo de um programa político e econômico de reestruturação urbana de acordo com os interesses do capital.

A linha de fronteira hoje possui uma definição essencialmente econômica - como a fronteira da lucratividade - mas adquire uma expressão geográfica bastante acentuada em diferentes escalas espaciais. Isto é, basicamente, o que a fronteira do século $X X$ $\left(\right.$ sic) ${ }^{*}$ e a assim chamada fronteira urbana têm em comum. $\mathrm{Na}$ realidade, ambas estão associadas à acumulação e expansão do capital. Mas enquanto a fronteira do século XIX representou a realização de uma expansão geográfica absoluta como a principal expressão espacial da acumulação de capital, a gentrificação e a renovação urbana representam o exemplo mais desenvolvido da rediferenciação do espaço geográfico com vistas ao mesmo resultado. É possível que, para compreender o presente, o que seja necessário hoje é a substituição de uma falsa história por uma geografia verdadeira.

\section{A reestruturação do espaço urbano}

É importante compreender a dimensão atual da gentrificação de modo a entender a natureza e a importância real do processo de reestruturação. Se por gentrificação entendermos, estritamente, a renovação residencial em bairros da classe trabalhadora, então, nos Estados Unidos (onde este processo é, provavelmente, mais intenso), ela aparece claramente no nível dos distritos censitários, mas não ainda em estatísticas metropolitanas (Chall, 1984; Schaffer e Smith, 1984). Para um certo número de cidades, nível de renda, aluguéis e outros indicadores do censo de 1980 oferecem evidências claras de gentrificação nas áreas centrais. Entretanto, o processo ainda não se tornou suficientemente importante a ponto de reverter, ou ao menos obstar de forma considerável, as tendências atuais de suburbanização residencial. Embora seja um padrão empírico interessante, de forma isolada este processo dificilmente significa uma transformação de maior alcance nos padrões de desenvolvimento urbano. Se, contudo, afastarmos a ideologia estreita promovida pela gentrificação, e vermos o processo a partir de algumas mudanças urbanas mais amplas, embora menos visíveis; se, em outras palavras, examinarmos o impulso do processo, e não dados empíricos estáticos, surge, então, um padrão coerente de uma reestruturação urbana muito mais significativa.

Antes de examinar as tendências exatas que estão conduzindo a um processo de reestruturação, é importante observar que a questão da escala espacial é fundamental em qualquer explicação relevante. Podemos afirmar que a reestruturação da economia espacial urbana é um produto do desenvolvimento desigual do capitalismo ou da operação de um rent gap; que ela é o resultado de uma economia de serviços em processo de desenvolvimento ou de mudanças nas preferências por estilos de vida; que esta reestruturação é resultado da suburbanização do capital ou da desvalorização do capital investido no ambiente construído. Obviamente, a reestruturação é um resultado, em alguma medida, de todas estas forças, mas afirmar isto acrescenta muito pouco. Estes processos ocorrem em escalas espaciais diferentes e, embora tentativas anteriores de explicação tenderam a se fixar a uma ou outra destas forças, elas podem, na verdade, não ser 
mutuamente excludentes. Autores que tentaram incorporar mais de uma destas forças geralmente se contentaram em listá-las como fatores. Esta versão da "análise de fatores" é, contudo, bastante desprovida de ambição. Todo o problema da explicação reside não em identificar fatores, mas em compreender a importância relativa e a relação estabelecida entre os assim chamados "fatores". Em parte, trata-se de uma questão de escala.

Mas existe uma segunda questão de escala concernente aos níveis de generalidade. Aceitamos, aqui, que a reestruturação do espaço urbano é geral, mas de forma alguma universal. Que significa dizer isto? Significa, em primeiro lugar, que a reestruturação do espaço urbano não é, estritamente falando, um fenômeno novo. Todo o processo de crescimento e desenvolvimento urbano consiste em um constante arranjo, estruturação e reestruturação do espaço urbano. O que é novo, hoje, é a intensidade em que esta reestruturação do espaço se apresenta como um componente imediato de uma ampla reestruturação social e econômica das economias capitalistas avançadas. Determinado ambiente construído expressa uma organização específica da produção e reprodução, do consumo e da circulação, e conforme esta organização se modifica, também se modifica a configuração do ambiente construído. A cidade dos pedestres, afirma-se, não é a cidade do automóvel, mas de forma ainda mais significativa, talvez, a cidade do pequeno artesanato não é a metrópole do capital multinacional.

A reestruturação geográfica da economia espacial é sempre desigual; portanto, a reestruturação urbana em uma região da economia nacional ou internacional pode não ser acompanhada, tanto em qualidade ou quantidade, natureza ou intensidade, por uma reestruturação em outra região. Isto é imediatamente evidente na comparação entre partes desenvolvidas e subdesenvolvidas da economia mundial. A estrutura básica da maioria das cidades do Terceiro Mundo e os processos em operação são muito diferentes da realidade na Europa, Oceania ou América do Norte. Mas, igualmente, no interior das economias desenvolvidas, há fortes disparidades regionais. Se Baltimore e Los Angeles estão ambas experimentando rápidas transformações em suas economias espaciais, também se pode afirmar que existem tantas diferenças quanto similaridades entre elas. Outras cidades, como Gary, em Indiana, podem estar sofrendo um declínio inexorável e mínima reestruturação (no lugar disso, uma contínua deterioração). Em resumo, há sobreposição de arranjos regionais e internacionais que complicam as configurações urbanas. Embora dêem ênfase às causas gerais e ao pano de fundo da reestruturação urbana contemporânea, as explanações oferecidas só poderão ter êxito na medida em que comecem a esclarecer a diversidade das formas urbanas que resultam do processo, assim como totais exceções à regra aparente. Isto, de novo, requer não uma "análise fatorial" (uma lista dos fatores), mas uma explanação integrada; devemos esclarecer não apenas a localização, mas também a temporalidade desta profunda transformação urbana. Mas talvez a distinção mais básica que surgirá é aquela entre as tendências que são predominantemente responsáveis peła ocorrência da reestruturação urbana e aquelas responsáveis pela forma que o processo assume.

Os mais importantes processos responsáveis pela origem e pela forma da reestruturação urbana podem, talvez, ser resumidos nos seguintes itens:

(a) a suburbanização e o surgimento de um diferencial de renda (rent gap);

(b) a desindustrialização das economias capitalistas avançadas e o crescimento do emprego no setor de serviços;

(c) a centralização espacial e simultânea descentralização do capital;

(d) a queda na taxa de lucro e os movimentos cíclicos do capital;

(e) as mudanças demográficas e nos 
padrões de consumo.

Em conjunto, estas transformações e processos podem proporcionar uma primeira aproximação de uma explicação integrada das diferentes facetas da gentrificação e da reestruturação urbana.

\section{Suburbanização e o surgimento do rent gap}

A explanação do desenvolvimento da suburbanização é mais complexa do que comumente se supõe, e uma alternativa revisionista às explicações tradicionais baseadas no transporte está começando a surgir (Walker, 1978, 1981). O objetivo aqui não é fornecer uma descrição minuciosa da suburbanização, mas sintetizar algumas das conclusões mais importantes.

O processo de suburbanização representa uma simultânea centralização e descentralização do capital e da atividade humana no espaço geográfico. Em uma escala nacional, a suburbanização é a expansão para além das áreas centrais, e este processo deve ser entendido, de forma geral, como um produto necessário da centralização do capital. É o crescimento dos vilarejos em cidades e das cidades em metrópoles.

Na escala urbana, no entanto, da perspectiva do centro urbano, a suburbanização é um processo de descentralização. É produto não do impulso elementar em direção à centralização, mas do impulso em direção a uma elevada taxa de lucro. A taxa de lucro varia conforme a localização, e na escala urbana como tal, o indicador econômico que diferencia um local do outro é a renda da terra. Muitas outras forças estiveram envolvidas na suburbanização do capital, mas a disponibilidade de terras mais baratas na periferia (menor renda da terra) foi primordial para o processo todo. Não havia nenhuma necessidade natural de a expansão da atividade econômica tomar a forma do desenvolvimento suburbano; não havia nenhum impedimento técnico que impossibilitasse um movimento do capital moderno de larga escala para o interior rural, ou impedindo que este capital redesenvolvesse a cidade industrial que herdou, mas, em vez disto, a expansão do capital conduziu a um processo de suburbanização. Isto, em parte, tem relação com o ímpeto à centralização (ver abaixo), mas, dada a economia da centralização, é a estrutura da renda da terra que determinou a expansão da atividade econômica para as áreas suburbanas.

O movimento do capital que leva ao desenvolvimento de atividades industriais, comerciais, residenciais e recreacionais nas áreas suburbanas resulta em uma mudança recíproca dos níveis de renda da terra nas áreas centrais e nas áreas suburbanas. Enquanto o preço da terra nas áreas suburbanas eleva-se com a proliferação de novas construções, o preço relativo da terra nas áreas centrais cai. Cada vez menores quantidades de capital são canalizadas para a manutenção e restauração dos edifícios localizados na área central. Isto resulta naquilo que denominamos um diferencial (rent gap) entre a atual renda da terra capitalizada pelo uso presente (deteriorado) e a renda da terra potencial que poderia ser capitalizada pelo "mais elevado e melhor" uso da terra (ou, ao menos, comparativamente "mais elevado e melhor" uso), em virtude da sua localização centralizada. Esta suburbanização ocorre paralelamente a mudanças estruturais nas economias avançadas. Alguns dos outros processos que examinaremos são mais limitados em abrangência; o que é digno de nota no que diz respeito ao rent gap é sua quase onipresença. A maior parte das cidades no mundo capitalista avançado experimentou tal fenômeno, em maior ou menor intensidade. Onde o processo é desobstruído para trilhar seu caminho em nome do livre mercado, ele leva a um abandono substancial das propriedades localizadas nas áreas centrais. Esta desvalorização do capital investido no ambiente construído afeta as propriedades de todos os gêneros: comercial e industrial, bem como residencial. Diferentes intensidades e formas de envolvimento do Estado conferem ao processo características muito diferentes em diversas economias, e o abandono (a conclusão lógica 
do processo) é mais marcante nos EUA, onde o envolvimento do Estado tem sido menos consistente e mais esporádico.

Em um nível mais básico, é o deslocamento do capital para a construção de paisagens suburbanas e o conseqüente surgimento de um rent gap o que cria a oportunidade econômica para a reestruturação das áreas urbanas centrais. A desvalorização da área central cria a oportunidade para a revalorização desta parte "subdesenvolvida" do espaço urbano. A realização efetiva do processo e a determinação de sua forma específica incluem os outros itens listados acima.

\section{Desindustrialização e o crescimento da economia terciária*}

Associado à desvalorização do capital investido nas áreas centrais está o enfraquecimento de certos setores econômicos e usos do solo em comparação com outros. Isto é resultado, essencialmente, de amplas transformações na estrutura econômica. As economias capitalistas avançadas (a grande exceção sendo o Japão), em particular, têm experimentado um início de uma desindustrialização, ao passo que houve uma paralela (ainda que parcial) industrialização de certas economias do Terceiro Mundo. A partir dos anos 1960, a maioria das economias industriais tiveram redução na proporção de trabalhadores empregados nos setores industriais (Blackaby, 1978; Harris, 1980, 1983; Bluestone and Harrison, 1982). Mas muitas áreas urbanas começaram a sofrer os efeitos da desindustrialização muito antes das últimas duas décadas. Assim, o crescimento da indústria, em escala nacional, desde a II Guerra Mundial, foi bastante assimétrico entre as regiões. Enquanto em algumas regiões, tais como a Midlands Ocidental e o sudoeste da Inglaterra, ou como muitos dos estados do sul e sudoeste dos EUA, houve um rápido crescimento da indústria moderna, outras regiões sofreram um desinvestimento relativo do capital investido na indústria. Na escala urbana o processo se mostra ainda mais marcante; a maior parte da expansão da capacidade industrial durante o boom do pósguerra não se instalou nas áreas mais centrais das cidades, o lugar tradicional da indústria segundo o modelo de Chicago de estrutura urbana, mas se localizou em áreas suburbanas e periféricas. O resultado disto foi um período de desinvestimento sistemático na produção industrial urbana que data, no caso de algumas cidades britânicas, mesmo de antes da I Guerra Mundial (Lenman, 1977). E isto ocorreu apesar de ter havido um aumento na produção industrial global da economia do Reino Unido, mesmo depois da II Guerra.

\section{A conseqüência}

desta desindustrialização é o crescimento do emprego em outros setores da economia, especialmente daquelas ocupações que têm sido definidas, imprecisamente, como de colarinho branco ou de serviços. No interior destas categorias amplas, muitos tipos de empregos diferentes estão incluídos: desde empregos em escritórios, serviços de comunicação e varejo até carreiras profissionais, de gestão e de pesquisa. No âmbito deste movimento abrangente em direção a um crescimento da força de trabalho no setor de serviços, portanto, existem tendências muito diversificadas, cada qual com expressões espaciais específicas, como veremos mais adiante. Por si só, os processos de desindustrialização e crescimento do emprego nos serviços não explicam, de modo algum, a reestruturação dos centros urbanos. $\mathrm{Na}$ verdade, esses processos ajudam a explicar, em primeiro lugar, os tipos de estoques de edifícios e usos do solo envolvidos no desenvolvimento do rent gap e, em segundo lugar, os novos usos do solo que devem surgir quando houver a oportunidade para o redesenvolvimento. Portanto, embora a ênfase da mídia tem sido na gentrificação recente e na renovação de habitações da classe trabalhadora, também ocorreu considerável transformação de uso em antigas áreas industriais. Isto não começou com a conversão de antigos armazéns industriais em finos lofts; muito mais significativo foi a anterior atividade de renovação urbana que, embora 
certamente se tratasse de um processo de remoção de cortiços, também foi a remoção de estruturas industriais obsoletas (isto significando também desvalorizadas), tais como fábricas, depósitos e ancoradouros, locais onde muitos dos moradores dos cortiços haviam, um dia, trabalhado.

Embora a desvalorização do capital e o surgimento do rent gap expliquem a possibilidade do reinvestimento na área central, ao redor da qual áreas gentrificadas estão se desenvolvendo, e embora as transformações econômicas e na estrutura de empregos indiquem os tipos de atividade que provavelmente se desenvolverão a partir deste reinvestimento, ainda persiste a questão de saber por que razão o crescente número de empregos no setor de serviços está, pelo menos em parte, sendo concentrado nas áreas centrais. A existência do rent gap é apenas uma explicação parcial; existe, afinal, terras baratas disponíveis em outros locais, por toda a periferia rural.

\section{Centralização espacial e descentralização do capital}

Com o surgimento do modo capitalista de produção, aquilo que até então havia sido contingente desaparece, é desconsiderado, ou então é convertido em uma necessidade. A acumulação da riqueza havia sido uma contingência no sentido de que, por mais que fosse um objetivo dos indivíduos, não era, nas sociedades pré-capitalistas, uma regra social geral da qual a sobrevivência da sociedade dependia. Com o advento do capitalismo, a acumulação de capital se converte em necessidade social exatamente desta maneira. Marx (1967 edn, vol. 1, cap. 25) demonstrou que uma certa concentração social e centralização do capital eram, ao mesmo tempo, um prérequisito e um produto da acumulação de capital. Em resumo, isto significa dizer que proporções progressivamente maiores de capital são controladas por um número cada vez menor de capitalistas.
A centralização social é realizada apenas através da produção de ordenamentos geográficos específicos, mas os arranjos espaciais resultantes são complexos. Basicamente, a centralização do capital conduz a uma dialética da centralização e descentralização espacial (N. Smith, 1982). Se a expansão do capital no século XIX é a manifestação mais clara do último processo (da descentralização), o desenvolvimento das metrópoles é o produto mais visível da centralização espacial. A centralização do capital ocorre em algumas escalas, contudo, diferentes da escala urbana. Ela ocorre na escala do chão da fábrica e na escala dos capitais nacionais em uma economia global, e em cada escala existem mecanismos bastante específicos que engendram o processo. Na escala urbana, as teorias tradicionais deram ênfase às "economias de aglomeração". A expansão do capital compreende uma progressiva divisão do trabalho, também em diferentes escalas, e, portanto, um número cada vez maior de atividades separadas devem ser combinadas a fim de prover as mercadorias e serviços necessários. Quanto menor for a distância entre estas diferentes atividades, menor será o custo e o tempo da produção e do transporte. Inserida neste contexto da acumulação de capital, esta explicação é essencialmente correta no que concerne à centralização original do capital em "aglomerações" urbanas.

Em um interessante insight, Walker (1981: 388) observa que

à medida que o capitalismo se desenvolveu, as economias de aglomeração diminuíram; elas são uma força historicamente contingente. Mas elas são, em parte, substituídas por economias (organizacionais) de escala com a concentração do capital, de modo que gigantescos nós de atividade ainda estruturam a paisagem urbana.

A idéia central aqui é que tais forças como as economias de aglomeração são historicamente contingentes. Vista da perspectiva do centro da cidade, a suburbanização da indústria representa um 
claro enfraquecimento das economias de aglomeração, e ela foi facilitada (e não "causada") por avanços nos meios de transporte. Vista da perspectiva da economia nacional, contudo, a suburbanização da indústria representou uma aglomeração de gigantescas (e não tão gigantescas) instalações industriais ao redor dos centros urbanos consolidados, e foi, portanto, uma reafirmação (nesta escala) do funcionamento das economias de aglomeração, ainda que enfraquecidas. O que Walker percebe, entretanto, é real; as economias de aglomeração operam de forma diferente hoje, com claras conseqüências espaciais. A mais óbvia destas conseqüências diz respeito às rápidas transformações nas configurações locacionais associadas à expansão do emprego no setor de serviços*.

O problema, no que tange ao emprego nos serviços, é que uma forte tendência para a centralização se combina com uma igualmente forte, ou até mais forte, tendência à descentralização: o movimento dos escritórios e outros empregos de serviços para os subúrbios. Como podem estas tendências aparentemente opostas coexistir? Como podem a suburbanização e a aglomeração ser coexistentes? A explicação para este aparente paradoxo reside na consideração de duas questões inter-relacionadas. A primeira é a relação entre espaço e tempo vis-à-vis às diferentes formas de capital e a segunda diz respeito à divisão do trabalho no interior dos assim chamados setores de serviços.

É um clichê, hoje, sugerir que a revolução nas tecnologias de comunicação levará a uma descentralização espacial dos escritórios. Esta aniquilação do espaço pelo tempo, como dizia Marx, de fato levou a uma enorme suburbanização dos empregos nos serviços, seguindo a suburbanização industrial. Com o uso do computador nos escritórios, este movimento continua. Mas, em consonância com a ideologia da sociedade sem classes que embasou a noção de colarinho branco, este movimento é geralmente tratado como a suburbanização de todo e qualquer tipo de trabalho em escritórios, desde altos cargos executivos até digitadores. Contudo, quanto mais o movimento de suburbanização se desenvolve, mais fica claro que esta noção é incorreta. Deste modo, a simultânea centralização e descentralização das atividades de escritórios é a expressão espacial da divisão do trabalho no interior da chamada economia de serviços. Geralmente, as atividades de escritórios que são descentralizadas são os sistemas e operações mais rotineiras associadas à administração, organização e gestão das atividades governamentais e corporativas. Estas representam os "back offices"*, as "fábricas de papel", ou, mais precisamente, as "fábricas de comunicação".

Muito menos comum é a suburbanização de centros decisórios como sedes de empresas e de órgãos governamentais. O boom dos escritórios experimentado por muitas cidades no mundo capitalista avançado nos últimos 15 anos parece ter sido deste tipo; trata-se da contínua centralização espacial dos centros decisórios mais importantes, assim como de uma miríade de serviços auxiliares a estas atividades: assessoria jurídica, serviços de publicidade, hotéis e centros de conferências, editoras, escritórios de arquitetura, bancos e serviços financeiros e muitos outros serviços relacionados aos negócios. Há exceções a esta regra, e uma das mais óbvias é Stamford, em Connecticut, que atraiu muitas novas sedes de corporações. Contudo, Stamford não é, de forma alguma, um caso comum. É, ao contrário, singular, justamente por ter atraído a descentralização de atividades administrativas e profissionais auxiliares fundamentais às sedes corporativas. O resultado é menos um processo de descentralização do que uma recentralização de funções executivas em Stamford. Se isto fortalece a tendência a uma "metrópole multimodal" (Muller, 1976) resta ainda a ser observado.

A questão que fica, então, é saber por que razão, com a descentralização de fábricas industriais e de comunicação, continua ocorrendo a centralização de núcleos decisórios, 
como sedes de empresas. As explicações tradicionais punham em evidência a importância do contato face a face. No entanto, embora a explicação baseada na necessidade do contato visual comece a identificar as questões relevantes, ainda é muito genérica. Esta explicação tende a evocar um certo sentimentalismo em relação ao contato visual, mas podemos ter certeza de que nenhum sentimentalismo pode explicar a concentração de arranha-céus nos distritos centrais de negócios (CBDs) contemporâneos. Por trás deste sentimentalismo encontra-se uma justificativa mais utilitária para o contato pessoal, e isso envolve as diferentes formas de administração do tempo nos diferentes setores da produção e circulação total do capital. Resumidamente, na fábrica industrial e nas fábricas de comunicação, o sistema em si (seja o maquinário, seja a agenda administrativa) determina os ritmos diários, semanais e mensais do processo de trabalho. Mudanças significativas nesta estabilidade de longo prazo advêm ou de decisões externas ou de rupturas internas periódicas como greves, falhas mecânicas ou falhas de sistema. A regularidade temporal destes sistemas de produção e administração, além do fato de dependerem de qualificações prontamente disponíveis na força de trabalho e de facilidades de transporte e comunicação com atividades auxiliares, torna a suburbanização uma decisão racional. Estas atividades têm pouco a ganhar ao se instalarem nas áreas centrais e, com os elevados aluguéis, teriam muito a perder.

Mas o ritmo temporal da administração superior da economia e de suas diversas unidades corporativas não é estável e regular desta maneira, para o desgosto dos administradores e executivos. Alterações nas taxas de juros e nos preços das ações, acordos financeiros, negociações trabalhistas e socorros financeiros (bailouts), transações internacionais no mercado de câmbio e no mercado de ouro, contratos comerciais, o comportamento imprevisível dos governos e dos competidores - todas estas atividades podem exigir uma rápida resposta por parte dos gestores de empresas, e isso, por sua vez, exige um contato próximo e imediato com uma série de sistemas de apoio profissionais e administrativos, assim como com empresas concorrentes. Nesse setor, e de formas múltiplas, o clichê "tempo é dinheiro" realiza-se de forma intensa (sobre a relação tempo e juros, ver Harvey, 1982:258). Menos comumente enunciada é a conseqüência de que o espaço também é dinheiro: a proximidade espacial reduz os tempos de decisão quando o sistema de decisão é suficientemente irregular a ponto de não poder ser reduzido à lógica de rotina do computador. O regime temporal anárquico da tomada de decisões financeiras na sociedade capitalista requer uma certa centralização espacial. Não se trata apenas do fato de que os executivos se sintam mais seguros quando enlatados como sardinhas em arranha-céus repletos de parceiros e concorrentes. Na verdade, eles estão mais seguros na medida em que a rápida tomada de decisões requer contato direto, informação e negociação. Quanto mais a economia mostra-se propensa a crises, e, portanto, à administração de crises de curto prazo, mais se pode esperar das sedes de empresas uma busca por segurança espacial. Juntamente com a expansão per se do setor e com o movimento cíclico do capital investido no ambiente construído, esta resposta espacial à irregularidade temporal e financeira ajuda a explicar o recente boom na construção de escritórios nas áreas centrais. "Colarinho branco" é um conceito visivelmente "caótico" (Sayer, 1982) com dois componentes distintos, cada qual possuindo uma expressão espacial.

Enquanto que na cidade pré-capitalista foram as necessidades da troca mercantil que ditaram o movimento de centralização espacial, e na cidade industrial capitalista foi a aglomeração do capital produtivo, na cidade capitalista avançada são os ditames financeiros e administrativos que perpetuam a tendência à centralização. Isto ajuda a explicar por que certas atividades chamadas de serviços são centralizadas e outras são suburbanizadas, e por que a reestruturação das áreas centrais assume esta forma corporativa/profissional. 


\section{A queda da taxa de lucro e o movimento cíclico do capital}

Tendo em vista, então, a natureza espacial do processo, como podemos explicar o momento específico desta reestruturação urbana? Esta questão depende do momento histórico do rent gap e do retorno espacial do capital para a área central. Longe de serem acontecimentos fortuitos, esses eventos são parte integrante do ritmo mais amplo da acumulação de capital. Em um nível mais abstrato, o rent gap resulta da dialética dos padrões espaciais e temporais do investimento de capital; mais concretamente, é o produto espacial dos processos complementares de valorização e desvalorização.

A acumulação de capital não ocorre de forma linear; trata-se de um processo cíclico formado por períodos de expansão e períodos de crise. O rent gap se desenvolve durante um longo período de expansão econômica, mas uma expansão que se dá em outro lugar. Portanto, a valorização do capital na construção dos subúrbios do pós-guerra ocorreu paralelamente à desvalorização do capital investido nas áreas centrais. Mas a acumulação de capital durante este período de crescimento leva a uma queda na taxa de lucro que começa nos setores industriais, e que conduz, em última instância, às crises (Marx, 1967 edn, vol. III). Como um meio de afastar a crise, ao menos temporariamente, o capital é retirado da esfera industrial e, como mostrou Harvey (1978, 1982), há uma tendência ao capital ser deslocado para a produção do ambiente construído, onde as taxas de lucro permanecem mais altas e onde é possível, através da especulação, a apropriação de renda da terra, apesar de nada ser produzido. Duas coisas se unem, então: no final de um período de expansão no qual o rent gap surge e cria a oportunidade para o reinvestimento, há uma tendência simultânea do capital em buscar uma saída no ambiente construído.

A remoção de cortiços e os projetos de renovação urbana em muitas cidades ocidentais no período posterior à II Guerra Mundial foram iniciados e conduzidos pelo Estado e, embora não sem relação com o surgin ento dorent gap, eles não podem ser explicados de forma adequada apenas nestes termos econômicos. Contudo, a função da renovação urbana foi preparar o caminho para a futura reestruturação que surgiria nos anos 60 e se tornaria mais visível nos anos 70. Em termos econômicos, o Estado absorveu os riscos iniciais associados à gentrificação, como no caso da Society Hill, na Philadelphia, que era um projeto de renovação urbana propriamente dito. O Estado também revelou ao capital privado a possibilidade de reestruturação em larga escala das áreas centrais, pavimentando o caminho para investimentos futuros de capital.

O momento desta reestruturação espacial, portanto, está intimamente relacionado à reestruturação econômica que ocorre durante as crises econômicas, como aquelas que a economia mundial experimentou a partir do início dos anos 1970. Uma economia reestruturada compreende um ambiente construído reestruturado. Mas não há transição gradual para uma economia reestruturada; a última crise econômica encontrou solução somente após uma destruição gigantesca de capital na II Guerra Mundial, representando uma desvalorização cataclísmica de capital e uma destruição que antecede uma reestruturação do espaço urbano. Hoje, 50 anos mais tarde, nos defrontamos novamente com a mesma ameaça.

\section{Mudanças demográficas e padrões de consumo}

O envelhecimento da geração babyboom, o elevado número de mulheres construindo carreira, a proliferação de famílias com uma ou duas pessoas e a popularidade do estilo de vida "solteiro urbano" são comumente considerados como os fatores que estão por trás da gentrificação. Em harmonia com a ideologia de fronteira, o processo é visto aqui como o resultado de escolhas individuais. Mas na verdade, esta explicação não é suficiente. Estamos assistindo a uma reestruturação 
urbana muito mais ampla em abrangência do que a reabilitação residencial, e é difícil ver como estas explicações poderiam ser, na melhor das hipóteses, mais do que parciais. Enquanto estas explicações podem ser apenas concebíveis no caso da St. Katherine's Dock, em Londres, elas são irrelevantes para compreender o boom de escritórios e a renovação das docas. No entanto, tudo isto está associado. As mudanças nos padrões demográficos e nas preferências de estilo de vida não são completamente irrelevantes, mas é crucial que entendamos o que estas transformações podem e o que elas não podem explicar.

A importância das questões demográficas e de estilo de vida parece ser fundamental na determinação da forma superficial assumida pela reestruturação, em vez de explicar a ocorrência da transformação urbana. Em vista do movimento do capital em direção às áreas centrais, e a ênfase nas funções executivas, profissionais, administrativas e de gestão, assim como outras atividades auxiliares, as mudanças demográficas e de estilo de vida podem auxiliar a explicar por que ocorre a proliferação de cafés chiques em vez de Harry Johnsons, de butiques de roupas de grife e gourmet shops requintados em vez de mini-mercados, de placas da American Express em vez de placas "aceitamos apenas dinheiro". Como sugere Jager (1986), a arquitetura das habitações gentrificadas é também um produto de uma cultura de classe específica e de um conjunto de estilos de vida. Portanto, alguns dos projetos de gentrificação mais recentes e menos elitizados, especialmente aqueles envolvendo novas construções, estão começando a reproduzir as piores habitações suburbanas do tipo caixa de fósforos, levando a uma suburbanização social e estética da cidade.

Sharon Zukin (1982a, 1982b) oferece uma ilustração excelente desta questão em sua análise do desenvolvimento da habitação em lofts no SoHo e em toda a área da Lower Manhattan. Sob o Lower Manhattan Plan, inspirado em Rockfeller e idealizado nos anos
1960, os antigos armazéns, ancoradouros e moradias de trabalhadores nesta área seriam demolidos em benefício dos usuais modos de construção centralizados, verticalizados, financeirizados e de alta tecnologia. A luta exitosa contra o redesenvolvimento foi travada em nome da "preservação histórica e das artes" e, em 1971, em decisão extraordinária, o SoHo foi considerado, no zoneamento, como "distrito de artistas". Entretanto, como aponta Zukin, isso não representa uma vitória da cultura (muito menos da "preferência do consumidor") sobre o capital. Na verdade, ela representou uma estratégia alternativa (envolvendo diferentes frações de capital) para a "recapitalização" da Lower Manhattan:

revalorização pela preservação, em vez de por meio de nova construção, se tornou um "compromisso histórico" nas áreas centrais... Na Lower Manhattan a luta para legalizar a moradia em lofts para artistas apenas antecipou, em alguma medida, uma resposta conjuntural à crise nos modos tradicionais do mercado imobiliário. Na verdade, a ampliação do mercado de lofts depois de 1973 proveu uma base para a acumulação de capital entre novos, ainda que pequenos, investidores.

Desde 1973, obviamente, grandes incorporadoras passaram a se envolver nesta área. Enquanto que antes cooperativas de lofts eram espontaneamente criadas por grupos de residentes interessados, hoje as incorporadoras renovam e adaptam um edifício e em seguida colocam-no no mercado, já acabado, como "cooperativa" (Co-op) ${ }^{8}$. E, evidentemente, cada vez menos moradores do SoHo são artistas, apesar do zoneamento que ainda persiste.

A questão aqui é que mesmo o SoHo, um dos símbolos mais vívidos da expressão artística na paisagem da gentrificação, deve a sua existência às mais básicas forças econômicas (ver também Stevens, 1982). A concentração de artistas no SoHo, hoje, é mais uma fachada do que a causa da popularidade 
da área. Isto fica evidente na exploração do simbolismo artístico da área na publicidade imobiliária agressiva.

\section{Direção e limites da reestruturação urbana}

Se a reestruturação que se iniciou prosseguir em sua atual direção, então podemos esperar mudanças significativas na estrutura urbana. Por mais preciso que o modelo de Chicago da estrutura urbana tenha sido, existe um consenso de que ele não é mais pertinente. O desenvolvimento urbano superou o modelo. A conclusão lógica da atual reestruturação, que permanece hoje incipiente, seria um centro urbano dominado por funções executivas, financeiras e administrativas de alto nível, habitações para a classe média e classe média alta, e um complexo de hotéis, restaurantes, cinemas, lojas e espaços de cultura oferecendo lazer a esta população. Em resumo, poderíamos esperar a criação de uma área de recreação burguesa, a Manhattanização social da área central para combinar com a Manhattanização arquitetônica que prenunciou a estrutura de empregos em transformação. A provável conseqüência disto é um deslocamento substancial da classe trabalhadora para os subúrbios mais antigos e para a periferia urbana.

Isto não pode ser entendido, como seguidamente o é, como um indício de que o processo de suburbanização está se encaminhando para um fim. Ao contrário, a agitação, durante os anos 1970, em torno do assim chamado "crescimento nãometropolitano" nos EUA representa menos uma reversão dos padrões de urbanização estabelecidos (Berry, 1976; Beale, 1977) do que um prosseguimento da expansão metropolitana muito para além dos limites estatísticos estabelecidos (Abu-Lughod, 1982). Não há muito sentido em supor que a suburbanização não será mais ampla do que nunca, caso venha a ocorrer um outro período de forte expansão econômica. Também não deve ser vista, esta configuração, como uma exclusão absoluta da classe trabalhadora das áreas centrais. Assim como firmes enclaves de habitações de classe média alta subsistiram nas áreas centrais amplamente habitadas pela classe trabalhadoras durante os anos 1960 e 1970, enclaves de comunidades da classe trabalhadora também permanecerão. De fato, estas comunidades terão sua função na medida em que os equipamentos e os serviços da área de recreação burguesa requerem uma população trabalhadora. A comparação - e o contraste com a África do Sul é instrutiva a este respeito (Western, 1981).

A alternativa oposta (de que as áreas centrais prosseguiriam em seu declínio absoluto em direção a um abandono amplo) pode ser viável apenas nos Estados Unidos. E elaé, de fato, uma possibilidade para algumas cidades nos EUA. Na medida em que a reestruturação do centro depende de uma contínua concentração e recentralização de funções econômicas de controle, pode-se esperar que isto ocorra com intensidade em centros nacionais e regionais. Mas a situação é menos evidente no caso de cidades industriais menores, como Gary, em Indiana, onde as funções administrativas e financeiras associadas às indústrias da cidade estão localizadas em outro lugar. Detroit fornece um exemplo ainda mais significativo, porque a suburbanização dos escritórios atingiu não apenas os "back offices", mas muitas das sedes corporativas, e os consideráveis esforços de recentralização, através do Renaissance Center inspirado em Ford, ainda não atraíram quantia substancial de capital para o centro de Detroit.

Não há, também, muito sentido em duvidar de que a rápida desvalorização do capital investido no ambiente construído das áreas centrais prosseguirá, apesar do início de um reinvestimento. Na atual crise econômica, com altas taxas de juros, não são apenas as novas construções que são adversamente afetadas. As mesmas forças provocam uma redução do capital investido na manutenção e reparo dos edifícios existentes, e a conseqüente desvalorização levará a uma expansão do "vale 
do valor da terra"8 dos edifícios fisicamente deteriorados; a extensão espacial na qual o rent gap opera é, então, estendida. Portanto, a reestruturação do espaço urbano conduz a uma simultânea, assim como subseqüente, decadência e redesenvolvimento, desvalorização e revalorização.

Em conclusão, salientamos que a reestruturação do espaço urbano é parte de uma evolução mais ampla da economia capitalista contemporânea. Assim sendo, no atual contexto de uma crise econômica que se aprofunda, nossas conclusões e especulações devem ser provisórias. É bem possível que a atual crise econômica resultará em forças políticas e econômicas, instituições e modos de controle muito diferentes, e isto poderia muito bem resultar em padrões de crescimento urbano muito diversificados. Em particular, pus ênfase aqui no pano de fundo econômico da reestruturação, em vez de tentar examinar as "coalizões políticas para o crescimento" (Mollenkopt, 1978, 1983) que executam planos de redesenvolvimento específicos. Isto foi, em parte, uma escolha de escala; não importa o quão geral seja o processo, as experiências locais diferem enormemente.

Além disso, a ênfase na lógica da acumulação e no seu papel na reestruturação urbana de forma alguma pressupõe uma adesão filosófica a uma abordagem fundada na "lógica do capital", ao invés de uma abordagem que coloque em evidência a luta de classes. Como uma dicotomia filosófica, esta questão é falsa; mas como uma dialética histórica, ela é tudo. A verdade lamentável é que os níveis comparativamente baixos das lutas da classe trabalhadora desde a Guerra Fria (com exceção daquelas durante o fim dos anos 1960, e em grande parte da Europa no início dos anos 1970) significaram que o capital teve, em boa medida, mãos livres na estruturação e reestruturação do espaço urbano. Isto não invalida o papel da luta de classes; significa que, com poucas exceções, se tratou de uma luta tão desequilibrada que a classe capitalista foi, em geral, capaz de levar a batalha a cabo por meio de suas estratégias econômicas de investimento de capital. O investimento de capital é a primeira arma de batalha no arsenal da classe dominante.

Uma exceção importante à hegemonia completa do capital diz respeito ao papel dos governos social-democratas na Europa em fornecer habitação pública, às lutas contra a privatização da habitação e às revoltas em várias cidades européias em torno da questão da habitação no início dos anos 80 . Estas questões não são abordadas aqui, e isto é uma omissão importante. O que esta experiência sugere, contudo, é uma progressão no nosso entendimento da fronteira urbana. A selva urbana produzida pelo movimento cíclico do capital e sua desvalorização se tornaram, do ponto de vista do capital, novas fronteiras urbanas da lucratividade. A gentrificação é uma fronteira na qual fortunas são criadas. Do ponto de vista dos moradores da classe trabalhadora e de suas comunidades, contudo, a fronteira urbana é mais diretamente política do que econômica. Ameaçados de serem desalojados pelo avanço da fronteira da lucratividade, a questão para eles é lutar pelo estabelecimento de uma fronteira política por trás da qual moradores da classe trabalhadora possam retomar o controle de seus lares: existem dois lados em qualquer fronteira. A tarefa mais ampla é de organizar o avanço da fronteira política, e como em qualquer fronteira, seja a de Turner ou a urbana, há períodos de calmaria e de agitação neste processo.

\section{Agradecimentos}

Peter Marcuse, Damaris Rose e Bob Beauregard fizeram valiosos comentários sobre os primeiros esboços deste trabalho. Também gostaria de agradecer aos membros de um seminário na Harvard University que ofereceram comentários, e membros dos departamentos de Geografia em Rutgers e Ohio State que auxiliaram a aprimorar os argumentos. 


\section{Notas}

'Fonte: Smith, N. Gentrification, the Frontier, and the Restructuring of Urban Space. In: Readings in Urban Theory edited by Susan S. Fainstein and Scott Campbell (Cambridge, Massachusetts: Blackwell Publishers, 1996)

2 John Wayne (1907-1979) foi ator de cinema e fez fama em filmes de faroeste. N.T.

3 A Wells Fargo é uma instituição financeira estadunidense que esteve envolvida com a "corrida pelo ouro" na Califórnia, durante o século XIX (naquela época atuava, além do ramo financeiro propriamente dito, no ramo de transporte, principalmente administrando linhas férreas). A instituição conserva o mesmo nome (e um poder imenso) até hoje, depois de múltiplas aquisições e fusões. N.T.

${ }^{4}$ Aqui é provável que o autor queira se referir à fronteira do século XIX, como aparece ao longo do texto, e não do século XX. N.T.
${ }^{5} \mathrm{O}$ autor utiliza a expressão "white-collar economy", literalmente "economia de colarinho branco". Por se tratar de uma expressão de uso incomum no português, preferimos traduzir por "economia terciária". N.T.

${ }^{6}$ Original "white-collar employment". N.T.

7Expressão já utilizada no vocabulário dos negócios para se referir às funções mais rotineiras de administração na divisão do trabalho no interior das empresas. N.T.

"Co-op", em inglês, designa um apartamento adquirido em regime de cooperativa, em muitos casos em edifícios de padrão elevado (o morador se torna membro da cooperativa proprietária do edifício). N.T.

9 No original "land value valley". N.T.

\section{Bibliografia}

Abrams, C. 1965. The city is the Frontier. New York: Harper \& Row.

Abu-Lughod, J. 1982. The myth of Demetropolitanization. Paper presented at the Symposimum on Social Change, University of Cincinnati.

Advisory Council on Historic Preservation 1980. Report to the President and the Congress of the United States. Washington, DC: Government Printing Office.

Anderson, J. 1983. Geography as ideology and the politics of crisis: the Enterprise Zones experiment. In: Redundant Spaces in Cities and Regions?, J. Anderson and R. Hudson (eds.), 313-50. London: Academic Press.

Banfield, E. C. 1968. The unheavenly city: The nature and future of our urban crisis. Boston: Little and Brown.

Beale, C. 1977. The recent shift of the United Sates population to non-metropolitan areas, 1970-75. International Regional Science Review 2 (2), 113-22.

Berry, B. J. L. 1976. The counterurbanization process: urban America since 1970. In Urbanization and Counterurbanization, B.
Berry (ed.), 17-30. Urban Affairs Annual Review, vol. II. Beverly Hills: Sage Publications.

Blackaby, F. (ed.) 1978. De-industrialization. London: Heinemann.

Bluestone, B. and B. Harrison 1982. The Deindustrialization of America: Plant closing, community abandonment, and the dismantling of basic industry. New York: Basic Books.

Butler, S. 1981. Enterprise Zones: Greenlining the inner cities. New York: Universe Books.

Castells, M. 1976a. The wild city. Kapitalistate 45 (Summer), 2-30.

Chall, D. 1984. Neighborhood changes in New York City during the 1970s. Quarterly Review of the Federal Reserve Bank of New York, Winter 1983-84, 38-48.

Gottmann, J. 1961. Megalopolis. The urbanized notheastern seabord of the United States. New York: Twentieth Century Fund.

Harris, N. 1980. Deindustrialization. International Socialism 7, 72-81.

Harris, N. 1983. Of Bread and Guns: The world economy in crisis. Harmondsworth: Penguin. 
Harvey, D. 1978. The urban process under capitalism: a framework for analysis. International Journal of Urban and Regional Research 2 (1), 100-31.

Harvey, D. 1982. The Limits to Capital. Oxford: Basil Blackwell.

Jager, M. 1986. Class definition and the esthetics of gentrification: Victoriana in Melbourne. In Gentrification of the City, N. Smith and P. Williams (eds), 78-91. Boston, London and Sydney: Allen \& Unwin.

Lenman, B. 1977. An Economic History of Modern Scotland, 1660-1976. Hamden, Conn.: Archon Books.

Long 1971 . The city as reservation. Public Interest 25, 22-38.

Marx, K. 1967 edn. Capital (3 volumes). New York: International Publishers.

Mollenkopt, J. H. 1978. The postwar politics of urban development. In Marxism and the Metropolis: New perspectives in urban political economy, W. K. Tabb and L. Sawyers (eds), 117-52. New York: Oxford University Press.

Muller, P. 1976. The outer city. Resource Paper 75-2. Association of American Geographers, Washington, DC.

Sayer, A. 1982. Explanation in economic geography: abstraction versus generalization. Progress in Human Geography 6 (March), 68-88.

Schaffer, R. and N. Smith 1984. The gentrification of Harlem. Paper presented at the annual conference of the American Association for the Advancement of Science, May 27.
Smith, N. 1982. Gentrification and uneven development. Economic Geography 58 (2) (April), 139-155.

Sternlieb, G. 1971. The city as sandbox. Public Interest 25, 14-21.

Stevens, E. 1982. Baltimore renovates, rebuilds and revitalizes. Art News 81 (8), 94-7.

Stratton, J. 1977. Pioneering in the Urban Wilderness. New York: Urizen Books.

Swierenga, R. 1968. Pioneers and Profits: Land speculation on the Iowa frontier. Ames, Iowa: Iowa State University Press.

Turner, F. J. 1958 edn. The Frontier in American History. New York: Holt, Rinehart \& Winston.

Wald, M. 1984. Back offices disperse from downtowns. New York Times (May 13).

Walker, R. A. 1978. The transformation of urban structure in the nineteenth century and the beginnings of suburbanization. In: Urbanization and Conflict in Market Societies, K. R. Cox (ed.), 165-211. London: Muthuen.

Warner, S. B. 1972. The Urban Wilderness: A History of the American city. New York: Harper \& Row.

Western, J. 1981. Outcast Cape Town. London: George Allen \& Unwin.

Zukin, S. 1982a. Loft living as "historical compromise" in the urban core: the New York experience. International Journal of Urban and Regional Research 6 (2), 256-67.

Zukin, S. 1982b. Loft Living: culture and capital in urban change. Baltimore: Johns Hopkins University Press.

Trabalho enviado em fevereiro de 2007

Trabalho aceito em março de 2007 
